Article

\title{
Probabilistic Health Risk Assessment of Vehicular Emissions as an Urban Health Indicator in Dhaka City
}

\author{
Asif Iqbal ${ }^{1, *}$, Shirina Afroze ${ }^{1}$ and Md. Mizanur Rahman ${ }^{2}$ (I) \\ 1 School of Natural and Built Environments, University of South Australia, SA 5095, Australia; \\ Shirina.Afroze@mymail.unisa.edu.au \\ 2 School of Natural and Built Environments \& Research Strand Leader: Natural and Built Environments \\ Research Centre (NBERC), University of South Australia, Mawson Lakes, SA 5095, Australia; \\ Mizanur.Rahman@unisa.edu.au \\ * Correspondence: Asif.Iqbal@unisa.edu.au
}

Received: 6 September 2019; Accepted: 13 November 2019; Published: 15 November 2019

check for updates

\begin{abstract}
Emissions modelling is an important tool for assessing the urban health status of any city, but often the assessments are affected by the uncertainty of the data used for the modelling. Therefore, a Monte Carlo simulation technique was used for a probabilistic emissions modelling of Dhaka City by simulating 20,000 scenarios for the highest and lowest values of traffic volume and speed profiles for each of the major road links. Only nitrogen oxide (NOx) emissions from on-road vehicles were considered, as vehicular sources are major contributors. Each dataset included two peak periods and an offpeak period of the day to cover the diurnal variation within each road link. Using the probability of the magnitude of emissions along with the corresponding health risk, a series of spatial urban health risk severity scenarios was generated for 2018 and 2024, suggesting that transportation and environmental planning is required for urban sustainability.
\end{abstract}

Keywords: stochastic modelling; probabilistic analysis; emissions; risk assessment

\section{Introduction}

In terms of transport choices, Dhaka City possesses characteristics similar to densely populated developing countries. In terms of its primary mode for urban commuting trips, per person space occupancy is the highest for cars $(75.8 \%)$, while for buses it is a modest $8.7 \%$ [1]. The growth of private vehicles has been significant in the past years to meet the demand caused by insufficient and inefficient public transport growth, and this has been aided by the economic solvency to buy private vehicles for reliable transport. Moreover, earlier developments in the city focused on the mobility of vehicles rather than emphasizing a modal shift from private to public transport. However, some recent public transport development projects, including Mass Rapid Transit (MRT) and Bus Rapid Transit (BRT), might influence the modal shift for daily commuters. Therefore, Dhaka City was selected for the research, as it could be used to assess the risk of vehicular emissions for a huge population group. At the same time, Dhaka could be used to assess the effectiveness of development strategies to improve urban health and assess whether they can provide a sustainable solution for the same population group.

In vehicle engines, fuels are burnt with a combination of air to facilitate complete combustion. The optimal air-to-fuel ration is called stoichiometric, while engines may operate at a rich stage (low air/fuel ration) or at a lean stage (high air/fuel ratio). More air in the process (i.e., a lean mixture) completes the combustion with greater heat, while reduced air in the process results in incomplete combustion [2], leading to increased levels of air pollutants. Nitrogen oxide (NOx), carbon monoxide (CO), volatile organic carbons (VOCs) and particulate matter (PM) are the main primary pollutants (and ozone $\left(\mathrm{O}_{3}\right)$ is a significant secondary pollutant) that are attributed to motor vehicles [2-9]. While 
vehicles contribute significantly to these emissions, anthropogenic NOx emissions are mostly linked to on-road vehicles [10]. Therefore, this research focused on NOx emissions only, leaving a scope for further research on other emissions. Vehicle NOx emissions are mainly comprised of nitric oxide (NO) and nitrogen dioxide $\left(\mathrm{NO}_{2}\right)$, of which $\mathrm{NO}$ is the dominant species (more than $90 \%$ for gasoline vehicles and more than $75 \%$ for diesel vehicles) [11,12].

NOx is a precursor of photochemical smog in large polluted cities. The effects of NOx are largely caused by smog, typically including severe coughing, asthmatic attacks and impaired lung function. An abundance of NOx with higher temperatures has been identified in different research works as a chronic cause of respiratory problems, a weakened immune system and lung cancer: these can become chronic with long-term exposure to $50-100 \mu \mathrm{g} / \mathrm{m}^{3} \mathrm{NOx}[3,13,14]$. Residents near roads in the city are susceptible to respiratory problems (coughing and wheezing) due to long-term exposure to NOx from vehicle exhaust $[3,15,16]$.

As vehicles contribute significantly to emissions of NOx, which are harmful for human health, city dwellers being exposed near roads and on roads to this pollutant is an important issue to be assessed. A monitoring network can determine the concentration, but an extensive network is required to cover a city, which is expensive. Thus, adopting a mesoscale emission inventory can solve the issue and account for all of the factors responsible for emissions, e.g., vehicle numbers, technology, fuel types and consumption rate. Considering that the average of a set of data provides a tentative inventory of average emissions, considering extensive data for each dataset would help in assessing the probability of generating that average emission. A high level of emissions can be accounted for on a road link in a mesoscale emissions inventory, but it might have a lower probability of occurrence. In that case, the risk of exposure to that emission is reduced, and this makes a probability analysis an important indicative factor in emissions inventories. A product of probability (of emissions) and its associated severity (in terms of health impact) would indicate the risk intensity for city dwellers for any road link, which was analysed spatially in this research.

A mesoscale emissions modelling approach for line sources considers the factors that influence emissions by identifying the characteristics of vehicle fleets for a zone or area. Identifying fleet characteristics and their operating patterns thus becomes important in this approach. However, there is room for uncertainty in characterization through surveys, as this assumes a scenario for a period based on a limited number of surveys. A Monte Carlo simulation technique can reduce the extent of that uncertainty $[17,18]$ through an analysis of thousands of scenarios within the range that is identified in the survey. Thus, a Monte Carlo simulation was used in this research to randomly generate thousands of scenarios that considered the highest and lowest values of traffic volume and speed profiles for each road link. Each dataset included two peak periods and an offpeak period of the day to cover the diurnal variation at each road link. The other factors that affect the rate of emissions, such as vehicle technology, fuel type and air conditioner usage patterns, were kept constant for all the simulations. The research also identified the extent of variation in emissions from probabilistic and non-probabilistic approaches, thus justifying the importance of such analyses in emissions modelling. This research aimed to assess the probability of health risks that might define the urban health status of the city, therefore indicating urban sustainability for present and future scenarios.

\section{Methodology}

For the probabilistic health risk assessment, the first step was conducting a probabilistic emissions inventory. With probabilistic emissions, on-road concentrations were estimated along with the extent of severity of that concentration. The probability and severity of NOx concentrations were finally analysed to assess the health risks on Dhaka City roads. For future traffic scenarios in Dhaka City, the probabilistic health risks were assessed following the same methods. 


\subsection{Probabilistic Emissions Inventory}

The emissions inventory conducted in this study was a mesoscale emissions inventory that considered city-level transport system characteristics for the calculation of NOx emissions using the standard vehicular emissions calculation methodology (Equation (1)) adopted by the European Environment Agency (EEA) for the European Monitoring and Evaluation Programme (EMEP) [19] (implemented in Dhaka City by Iqbal et al. [6]).

$$
\text { Emissions, } \mathrm{E}_{(\mathrm{k}) \mathrm{NOx}}(\mathrm{gm} / \mathrm{km} / \text { day })=\sum_{(j)}^{(i)} A A D T_{i j} \times E F_{i j}
$$

where,

$i=$ all vehicle types being considered (e.g., private car, taxi, bus, truck);

$j=$ all fuel types being considered (petrol, diesel, Compressed Natural Gas- CNG);

$k=$ the road link of interest for emissions calculations;

$A A D T=$ average annual daily traffic (number) along road link of vehicle type $i$ and fuel type $j$; and $E F_{i j}=$ base emissions factor for vehicle type $i$ and fuel type $j(\mathrm{gm} / \mathrm{km})$.

The input parameters for the mesoscale emissions inventory demanded detailed data for Dhaka City's transport system characteristics. As can be seen in Equation (1), traffic volume (AADT) and emission factors are the determining factors for emissions calculations. The emission factors are also dependent on the vehicle and fuel type and the speed profile of vehicles.

The fuel consumption-based emissions factor (gm of emissions/gm of fuel consumed), which was scaled for Dhaka City, was developed by Iqbal et al. [6] and is provided in Table 1. The EEA [19] provides the vehicle type/fuel-specific fuel consumption rate of vehicles in relation to the speed of vehicles (also provided in Table 1). Considering the speed profile of vehicles running on different road links, the NOx emissions (gm of emissions/km travelled) for each road link were calculated.

Conducting several surveys might have provided representative values for the traffic volume and speed profile of vehicles; however, the chance of not being representative would still exist. To overcome this, a Monte Carlo simulation method (a stochastic modelling approach) was adopted in this research, and probabilistic input values were obtained by randomizing the vehicle/fuel-specific traffic volume and speed profiles for each road link (discussed in detail in the following section). Thus, the inventory represented probabilistic NOx emissions for each road link.

\subsubsection{Data for Analysis}

For gross traffic volume, year-wise total registered vehicles in Dhaka City (up to 2018) were obtained from the Bangladesh Road Transport Authority (BRTA). These gross traffic data were useful in predicting the growth trends of different vehicle categories in the city, which are represented graphically in Figure 1. The growth trends were used for predicting future vehicle numbers in the city, which was required in this research for the future scenario analyses. 
Table 1. Nitrogen oxide (NOx) emissions factors (gm of emissions/gm of fuel consumed) for vehicles in Dhaka City and the fuel consumption relationship with average vehicle speed $(v)$.

\begin{tabular}{|c|c|c|c|c|c|c|c|c|}
\hline & \multirow{2}{*}{$\begin{array}{l}\text { NOx Emissions } \\
\text { (gm/gm of Fuel) }^{N 1}\end{array}$} & \multirow{2}{*}{$\begin{array}{l}\text { Fuel Consumption } \\
(\mathrm{FC})(\mathrm{gm} / \mathrm{km})^{\mathrm{N} 2}\end{array}$} & \multicolumn{6}{|c|}{ FC Equation Variables and Their Values for Different Vehicles ${ }^{b}$} \\
\hline & & & a & $\mathbf{b}$ & c & $\mathrm{d}$ & e & f \\
\hline \multicolumn{9}{|l|}{ Gasoline } \\
\hline \multicolumn{9}{|c|}{ Passenger Car (Euro 2/Euro 4) } \\
\hline$<1.4 \mathrm{~L}^{\circ}$ & $0.016878 / 0.001107$ & $\left(a+c \times v+e \times v^{2}\right) /(1+$ & 208/136 & $0.107 / 0.026$ & $-0.565 /-1.65$ & $-0.0005 / 0.000228$ & $0.0143 / 0.0312$ & \\
\hline $1.4-2.0 \mathrm{~L}$ & $0.014768 / 0.000939$ & $\left.b \times v+d \times v^{2}\right)$ & $347 / 174$ & $0.217 / 0.0685$ & $2.73 / 0.364$ & $-0.00091 /-0.000247$ & $0.00428 / 0.00874$ & \\
\hline$>2.0 \mathrm{~L}$ & $0.012658 / 0.000674$ & & $1540 / 285$ & $0.869 / 0.0728$ & $19.1 /-0.137$ & $-0.00363 /-0.000416$ & & \\
\hline $\begin{array}{l}\text { LDV } \\
\text { (Conventional/Euro 4) }\end{array}$ & $0.012658 / 0.00064$ & $\begin{array}{l}\left(a+c \times v+e \times v^{2}\right) /(1 \\
\left.+b \times v+d \times v^{2}\right)\end{array}$ & $1540 / 285$ & $0.869 / 0.0728$ & $19.1 /-0.137$ & $-0.00363 /-0.000416$ & & \\
\hline $\begin{array}{l}\text { MC-4 (> } 50 \text { cc) (Euro } \\
\text { 2/Euro 4) }\end{array}$ & $0.021097 / 0.005388$ & $\begin{array}{l}a+b \times v+c \times v^{2}+d \\
\times v^{3}+e \times v^{4}+f \times v^{5}\end{array}$ & $87.94 / 81.14$ & $-4.081 /-3.764$ & $0.1095 / 0.1009$ & $-0.001543 /-0.001423$ & $\begin{array}{l}1.15 \times 10^{-5} / 1.06 \times \\
10^{-5}\end{array}$ & $\begin{array}{l}-3.442 \times 10^{-8} /-3.17 \\
\times 10^{-8}\end{array}$ \\
\hline \multicolumn{9}{|l|}{ Diesel } \\
\hline $\begin{array}{l}\text { LDV } \\
\text { (conventional/Euro 3) }\end{array}$ & $0.083436 / 0.011573$ & $\begin{array}{l}0.02113 v^{2}-2.65 v+ \\
148.91\end{array}$ & & & & & & \\
\hline $\begin{array}{l}\text { HDV Truck (Euro } \\
\text { 1/Euro 3) }\end{array}$ & $0.041718 / 0.02104$ & $\left(\left(a \times\left(b^{v}\right)\right) \times\left(v^{c}\right)\right)$ & $1324.255 / 1065.897$ & $1.012839 / 1.01741$ & $8-0.8054 /-0.85958$ & & & \\
\hline $\begin{array}{l}\text { HDV Bus (Euro } \\
\text { 1/Euro 3) }\end{array}$ & $0.012564 / 0.025628$ & $\left(\left(a \times\left(b^{v}\right)\right) \times\left(v^{c}\right)\right)$ & $4075.513 / 2256.533$ & $1.012972 / 1.01074$ & $9-0.9355 /-0.80861$ & & & \\
\hline \multicolumn{9}{|l|}{ CNG } \\
\hline $\begin{array}{l}\text { Passenger Car (Euro } \\
\text { 2/Euro 4) (all } \\
\text { capacities) }\end{array}$ & $0.0105 / 0.001105$ & $\begin{array}{l}0.00720 v^{2}-0.9250 v+ \\
74.625\end{array}$ & & & & & & \\
\hline $\begin{array}{l}\text { LDV }(>2.0 \mathrm{~L} \text { ) (Euro } \\
\text { 2/Euro } 4 \text { ) }\end{array}$ & $0.009 / 0.00063$ & $\begin{array}{l}0.00720 v^{2}-0.9250 v+ \\
74.625\end{array}$ & & & & & & \\
\hline HDV bus (Euro 4 ) & 0.0114 & $\left(\left(a \times\left(b^{v}\right)\right) \times\left(v^{c}\right)\right)$ & $4075.513 / 2256.533$ & 1.012972/1.01074 & $9-0.9355 /-0.80861$ & & & \\
\hline $\begin{array}{l}3 \mathrm{~W}(<1.4 \mathrm{~L}) \text { (Euro } \\
\text { 2/Euro 4) }\end{array}$ & $0.0105 / 0.001105$ & $\begin{array}{l}0.00720 v^{2}-0.9250 v+ \\
74.625\end{array}$ & & & & & & \\
\hline
\end{tabular}

Note: HDV, heavy-duty vehicles; LDV, light-duty vehicles; 3W, three-wheeler vehicles; CNG, compressed natural gas; MC, motorcycle. Source: (N1) adapted from Iqbal et al. [6]; (N2) the European Environment Agency (EEA) [19] 


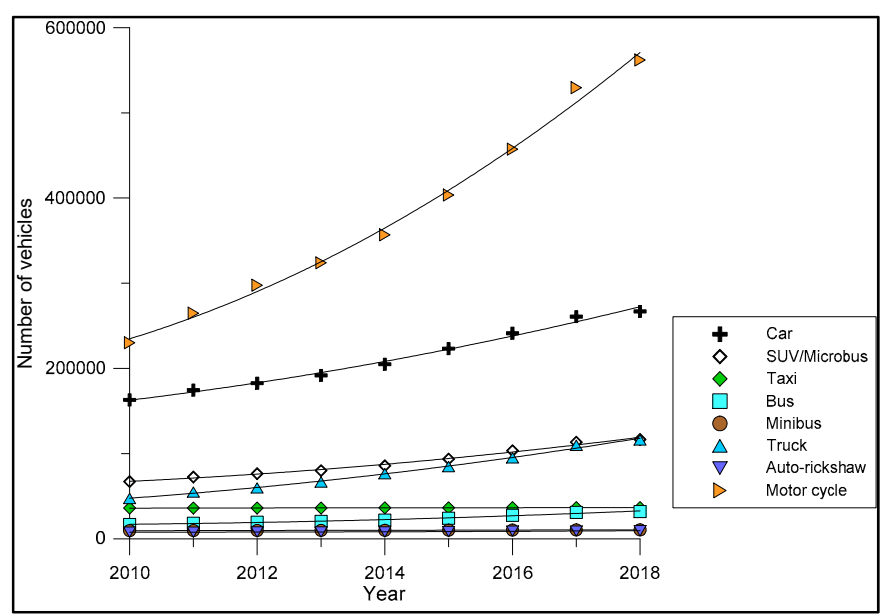

Figure 1. Growth trends of total numbers of registered vehicles in Dhaka (2010-2018) (data source: the Bangladesh Road Transport Authority (BRTA) 2018) [20].

However, for a spatial distribution of emissions in the city, a distribution of vehicles along the routes in the city is required. Iqbal et al. [6] conducted a midblock traffic count survey in Dhaka City in 2012-2013 and accounted for vehicle-specific traffic volume at major road links of the city. The research articulated the methodology of conducting the survey and justified its validity to represent the spatial distribution of traffic volume in the city. However, understandably, the number of samples collected during the survey was limited, which created a corridor of uncertainty, as the traffic volume may not have been precise on all of the days. Therefore, an average of numerous samples would reduce that uncertainty and would make the samples more representative. This research considered the same road links in analysing the probability of emissions (Figure 2), which spatially covered the city and took all the major roads into account.

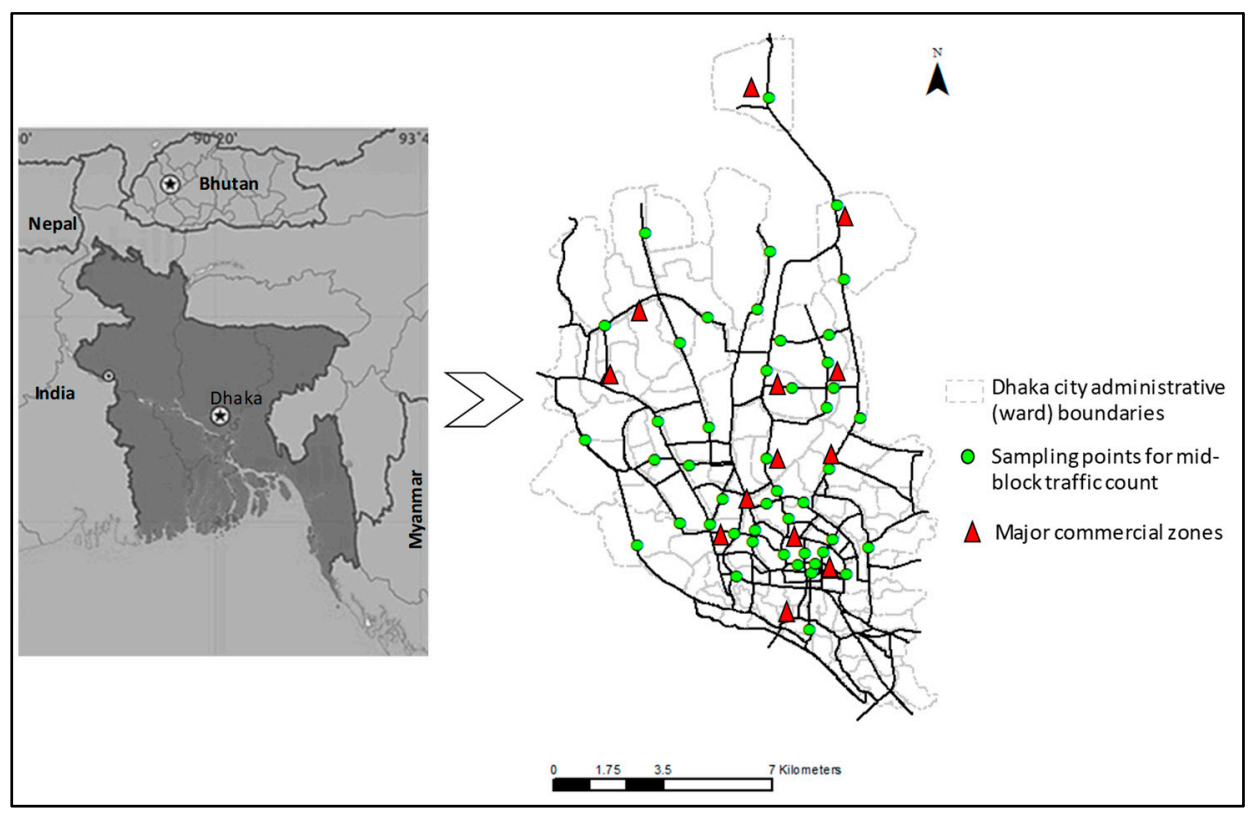

Figure 2. Map demonstrating Dhaka's location in Bangladesh and map of Dhaka City's major road networks (and the datapoints considered in the emissions assessment). Source: Bangladesh location map adopted from Maphill [21]; commercial zoning information adopted from Japan International Cooperation Agency- JICA [22]. 
Dhaka, the capital, is situated in the central part of Bangladesh (Figure 2). It represents a typical megacity in a developing country, where the centralization of facilities is the key reason for a very high population. The city provides space for everything, including residential areas, commercial areas and industries. The road network is quite widespread, with some major arterial roads connecting the city (Figure 2). Dhaka's city structure is very much mixed in nature, and very few places are dedicated solely for any specific use. However, there are some commercially dominant zones in the city that influence the flow of traffic. The points on the map in Figure 2 are indicative of the positions of those commercial zones, which are in fact more dispersed than the areas indicate. Besides, the volume and characteristics of vehicles on roads differ based on the functionality of different zones. For instance, despite being a commercial zone, old Dhaka (the southern portion of the map) is mainly dominated by different businesses and street markets on narrow roads: nonmotorized rickshaws pull carts, and similar nonmotorized conveyances dominate the traffic flow.

A Monte Carlo simulation method was applied to generate random data within the range obtained from the survey. Since a random function can produce randomly higher or lower values, a lower number of iterations (i.e., generating a lower number of random values) might lead to fluctuations in the results. While four simulations were tested for a sample road link to account for NOx emissions, the results (Figure 3) demonstrate that the output became stable with more than 10,000 iterations (i.e., considering more than 10,000 random samples). Therefore, as a conservative approach, the stochastic model was simulated 20,000 times for a stable representative value.

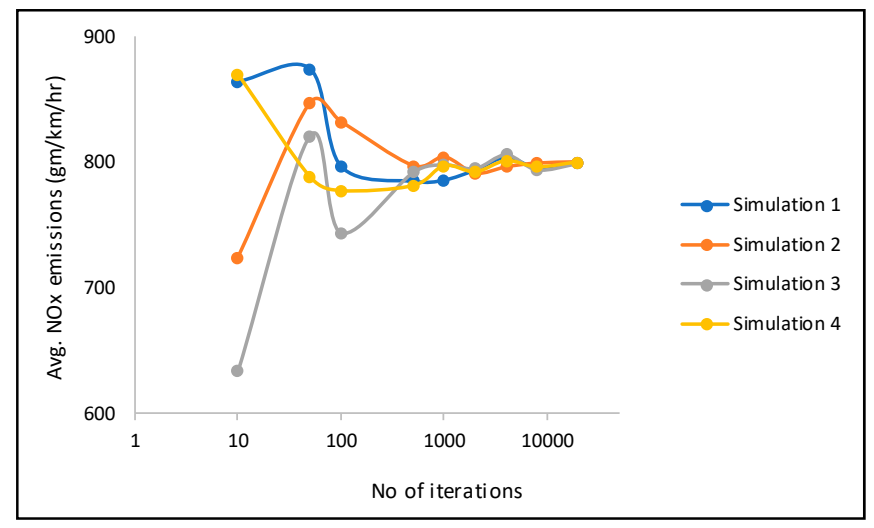

Figure 3. Stability of the stochastic model in relation to the number of random samples (iterations): the stability is shown here based on the average emissions generated for a single road link from compressed natural gas (CNG)-driven private cars only.

Considering the change in traffic volume in Dhaka since 2012, the traffic volumes for sample road links were calculated proportionately for subsequent years. For each road link and each vehicle category, the traffic volume was generated randomly 20,000 times based on the highest and lowest values of vehicle numbers projected for that year (from the 2012 survey data on these road links).

Since the magnitude of the traffic volume is generally different for peak and off-peak periods (for instance, peak is 09:00-11:00, 13:00-14:30 and 17:00-19:00; off-peak is 08:00-09:00, 11:00-13:00, 14:30-17:00 and 19:00-21:00), data were generated separately for the two classified periods of the day considering the corresponding range of traffic volumes.

Second-by-second speed profiles for vehicles on the road in 2012 were also estimated by Iqbal et al. [6], which was done by collecting a small number of samples. Since data were not collected as part of this study, therefore a similar traffic characteristic was assumed for subsequent years. Iqbal and Allan [23] developed a relationship for the average speed of vehicles against vehicle volume (car equivalent (Ce)) on the road, as stated in Equation (2), which was applied in this research to adjust the 
speed profiles of vehicles on the road for subsequent years. The probabilistic speed profiles for peak and offpeak periods were obtained similarly by applying a Monte Carlo simulation (run 20,000 times):

$$
v=-0.0495 C e+48.505
$$

where,

$v=$ vehicle average speed $(\mathrm{km} / \mathrm{h})$;

$\mathrm{Ce}=$ car equivalent of vehicles running on the road (equivalent number of cars that can be substituted tentatively for the length of different categories of vehicles running on the road in Dhaka City, i.e., bus $=2.5 \mathrm{Ce}$, truck $=2 \mathrm{Ce}$ and $\mathrm{MC}=0.4 \mathrm{Ce})[23]$.

The traffic data for 2024 scenarios, considering the future transport plans of the city, were projected based on the growth trends depicted in Figure 1. Over the years, the growth pattern of vehicles varies during different periods, aligning with policies or socioeconomic factors. However, this study considered the 8-year growth trend for different vehicle categories, which may justify trends in the future. In order to validate the outcome of the vehicle growth trends (Figure 1), this study estimated data for previous years (2004 and 2008) and compared those to known traffic volumes from those years. In Figure 4, the monitoring data are depicted as "actual" data, and values estimated by the trend are "calculated" data. A comparison of the results to the actual data showed that in the maximum number of cases, the calculations overestimated the values. The comparison in Figure 4 was done for private vehicles and motorcycles only, as these vehicles showed rapid growth over the years. Since the difference was insignificant, the projection method was therefore considered to be legitimate and conservative.

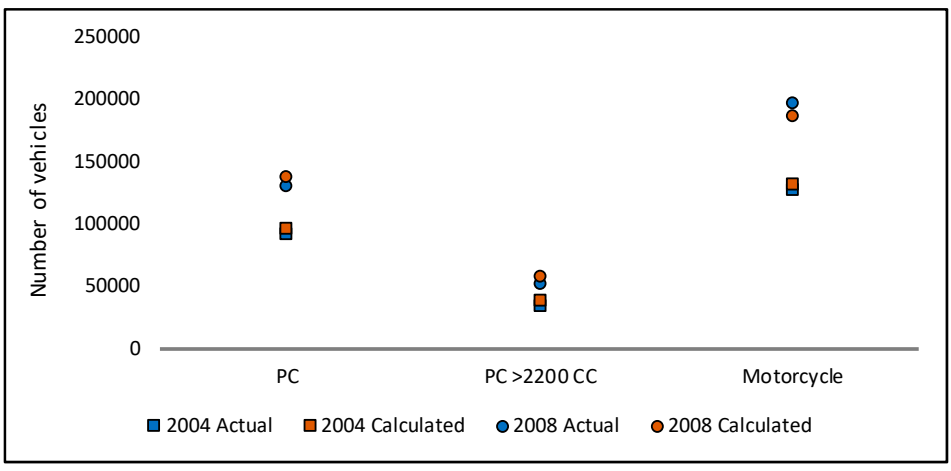

Figure 4. Comparison of calculated data to actual traffic volume data for different vehicle categories in Dhaka City.

\subsubsection{Estimating On-Road NOx Concentrations}

The NOx concentrations on and near roads were estimated using the Gaussian line source pollution dispersion model CALINE4 [24] (considering emissions, road link characteristics, traffic volumes and meteorological conditions):

CALINE4 is recommended by the US EPA (Environment Protection Authority) for use in urban areas with simple terrain and transport distances of less than $50 \mathrm{~km}$ [25], while the pollutants are inert gases;

Data for wind speed, wind direction, wind direction standard deviation, atmospheric stability class, mixing height and temperature were collected from the Bangladesh Bureau of Meteorology [26];

$\bigcirc \quad$ The model was run for $1 \mathrm{~h}$ (average concentration), which provided a 24-h average concentration of running the model for peak and offpeak periods;

- It is important to note that $\mathrm{NOx}$ is converted to $\mathrm{O}_{3}$ in the presence of sunlight, which might show a reduced ambient NOx concentration on a sunny day. In Bangladesh, generally May to 
September of each year is a period with a very low count of sunny days [27]. However, a constant conversion of $\mathrm{NOx}$ to $\mathrm{O}_{3}$ throughout the year was considered for this research (rate as suggested by CALINE4) irrespective of the number of sunny days. Although considering a constant rate of conversion might not be an accurate approach, applying it prevented an overestimation of the NOx concentration in an overall scenario analysis;

- CALINE4 was run for two different meteorological conditions in a year. The variation in meteorological data is provided in Figure 5, showing distinct wind speed and direction differences during wet and dry months. Therefore, the model was run considering the meteorological conditions of November and July and was assumed to be applicable for November-March (dry months) and April-October (wet months), respectively. The average hourly concentration for these two periods was considered to be the average concentration for the year;

- The model was run with a background NOx concentration of $0.02 \mathrm{ppm}$. This is not the exact measurement for Dhaka, but it was applied considering the relative pollution contribution of other sources $[28,29]$ and was fractioned in relation to the national standard $(0.1 \mathrm{ppm})$.

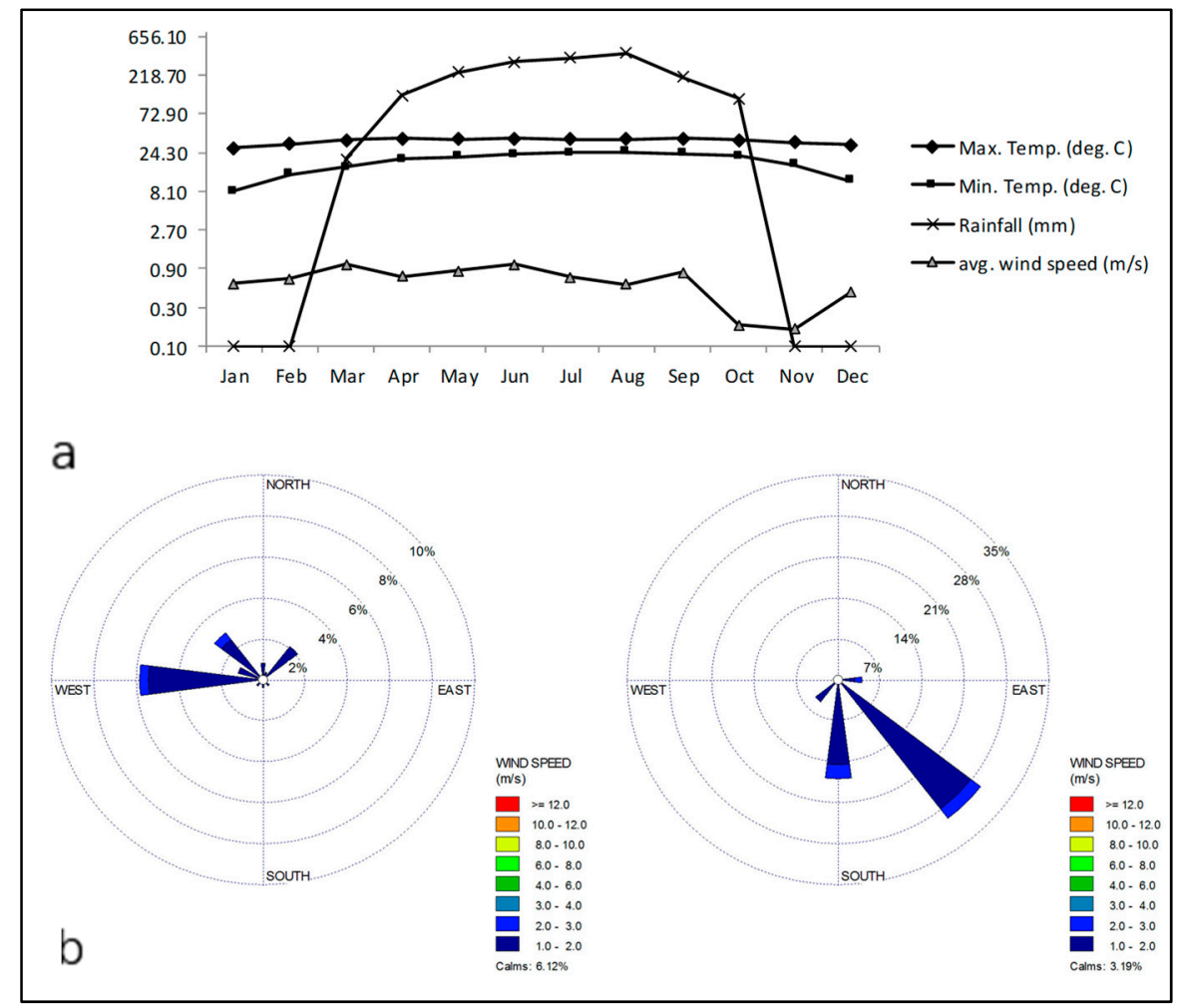

Figure 5. (a) Average monthly meteorological data for Dhaka City in Bangladesh; (b) wind direction map for November (left) and July (right) (data source: Bangladesh Meteorological Department (BMD) [26]).

\subsection{Probability Function and Distribution}

In order to assess the nature of the probability distribution, it was important to identify how the input parameters (traffic volume) were distributed. Analysing the histograms of the field sample data, the traffic volumes were assumed to be normally distributed in most of the cases, although some of the samples showed a slightly skewed distribution. As an example, the distributions for different road links are shown in Figure 6 below. 


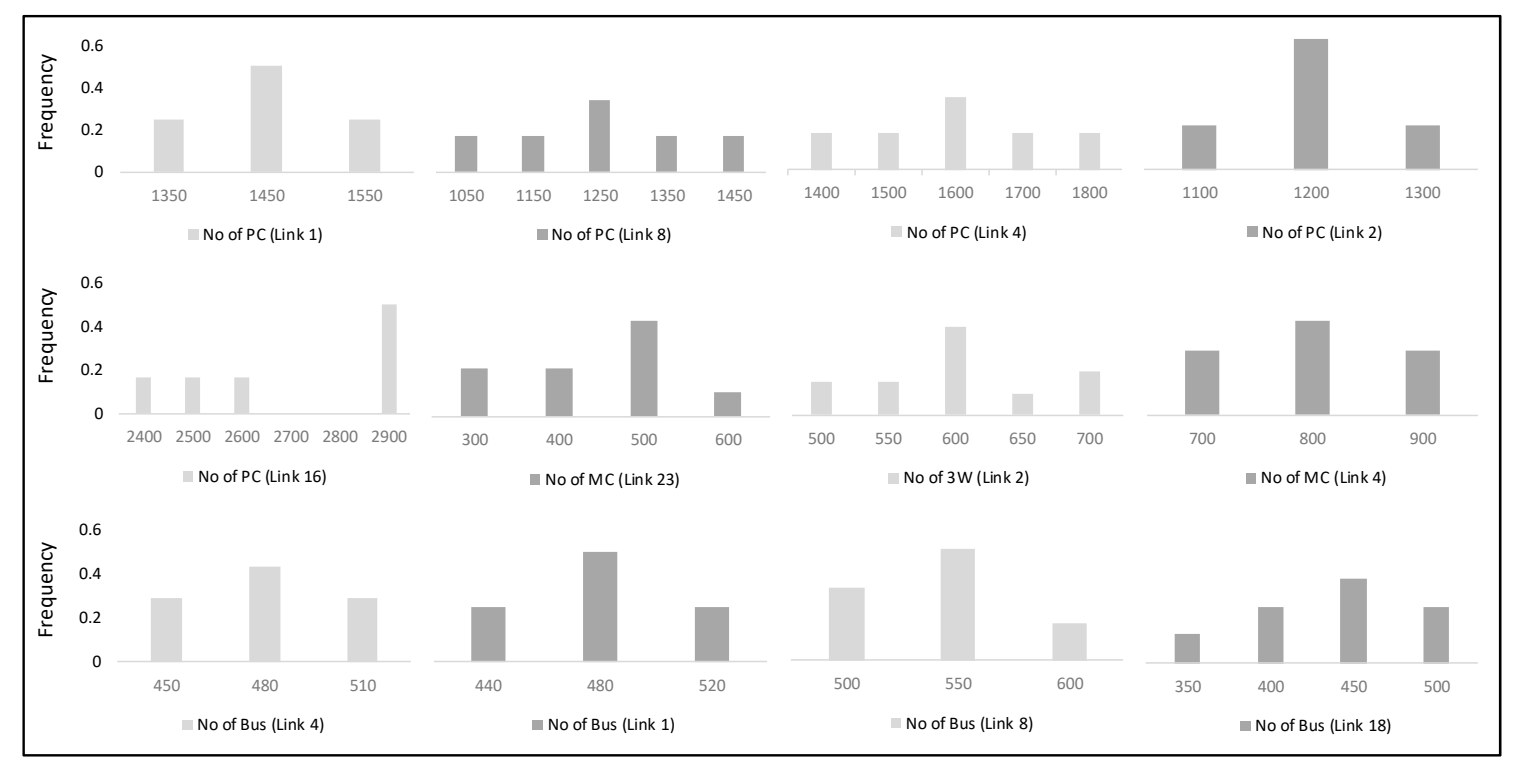

Figure 6. Histogram of traffic volume obtained from a survey of different road networks, indicating a normal distribution of the samples.

However, to simplify, the distributions were considered to be normal in this research. Hence, the calculated emissions were similarly distributed, and therefore, the probability of risk was analysed with a cumulative distribution function of normally distributed NOx emissions (Equation (3)), where emissions equivalent to the national standard or the WHO (World Health Organization) standard on the cumulative curve indicated the probability of risk:

$$
F(x)=\int_{-\infty}^{x} \frac{e^{\frac{-(x-\mu)^{2}}{2 \sigma^{2}}}}{\sigma \sqrt{2 \pi}}
$$

where $x$ represents NOx emissions and $\mu$ and $\sigma$ are the mean and standard deviation of NOx emissions.

The cumulative distribution function generated a chart representing NOx emissions against the probability of their occurrence. Thus, the distribution was indicative of the probability of threshold NOx emissions levels that were equal to the standard concentration. Therefore, the

Probability of exceedance above standard $=1-$ Probability of emissions at the standard level

A computing code was developed in Visual Basic that was capable of generating 20,000 random values (for both traffic volume and vehicle speed) for each road link and for each vehicle category and generating the resulting cumulative distribution function for each road link. The developed tool pack could run about 9 million simulations for each desired output and save the distributions in an excel file when the input data were provided in a prescribed format. The tool pack increased the efficiency of the calculation process, while a big dataset could be generated and analysed very quickly. A schematic diagram of the algorithm for assessing the probability of emissions exceedance is provided below in Figure 7. 


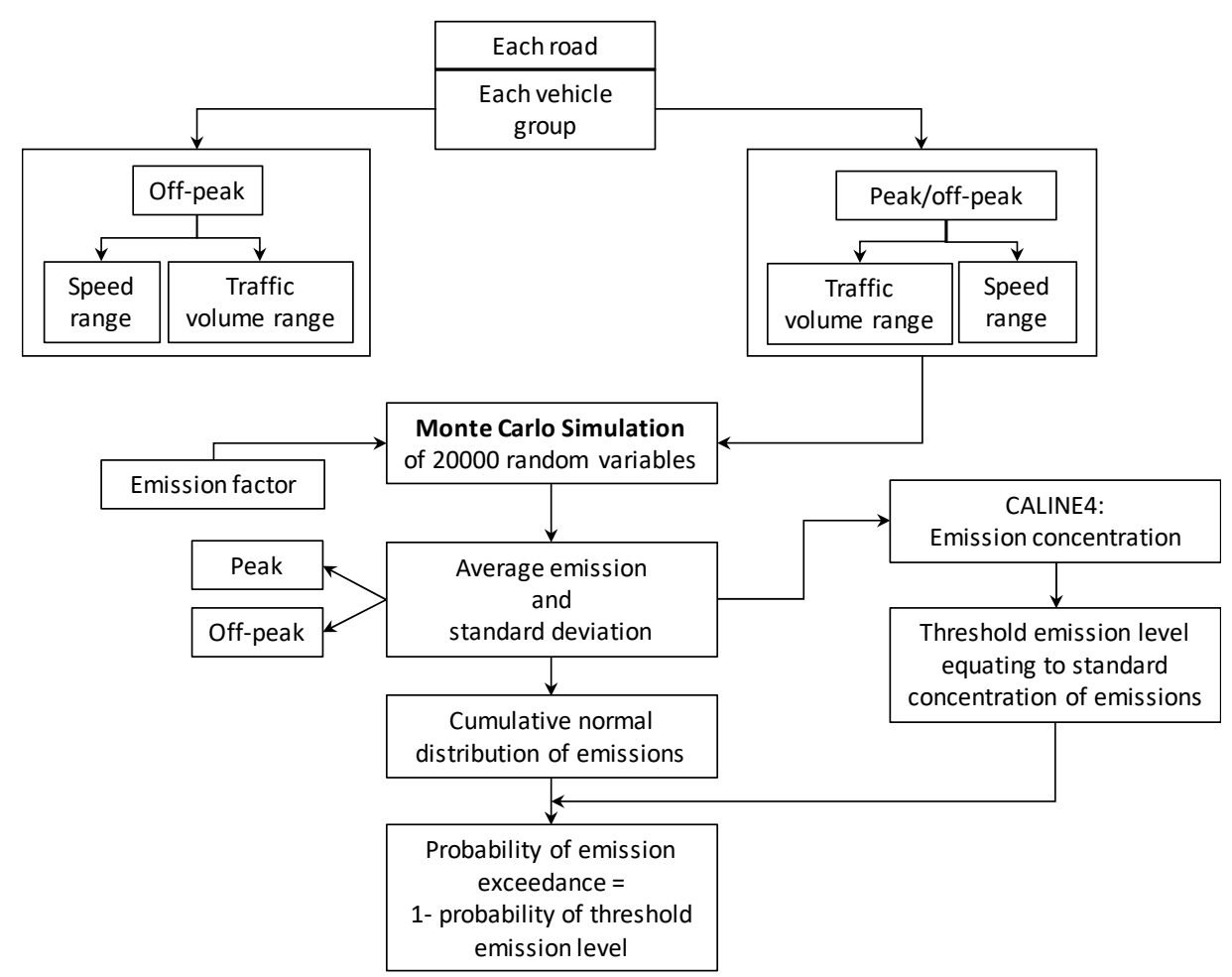

Figure 7. Schematic diagram of the developed tool pack for assessing the probability of emissions exceedance.

\subsection{Risk Analysis}

The risks of vehicular emissions to human health and the environment were assessed by analysing the probability of emissions exceedance above the standard level. In a risk analysis, risk is considered high when both the severity and probability are high:

- The severity here was associated with the standard level of emissions and was scaled to the magnitude of emissions, as classified below. The National Ambient Air Quality Standard of Bangladesh for NOx is $0.1 \mathrm{ppm}$ and $0.053 \mathrm{ppm}$ for the hourly and yearly average, respectively $[30,31]$ :

Severe-4: hourly emissions concentration $>0.25 \mathrm{ppm}=\mathrm{WHO}$ guideline value for acute health effects [31] or 24-h concentration $>200 \%$ of annual standard;

- Critical-3: emissions concentration $>150 \%$ of the standard;

- Marginal-2: emissions concentration at the level of the standard;

- Negligible-1: emissions concentration below the level of the standard;

- Probability indicated the likelihood of generating the severity and was scaled based on its percentage of occurring, as follows. There is no standard method for scaling probability; however, the probability of risk is scaled in project management practices $[32,33]$ and was used as a reference for scaling the probability in this research. This is an evenly distributed scale for higher ranges that is capable of distinguishing between the occurrences of emissions scenarios:

Strong-5: probability $\geq 80 \%$;

High-4: probability $\geq 60 \%-<80 \%$;

Medium-3: probability $\geq 40 \%-<60 \%$;

Low-2: probability $\geq 10 \%-<40 \%$;

Improbable-1: probability $<10 \%$; 
- Considering the severity and probability of emissions, a risk analysis matrix was generated (Table 2) that showed risk indexes for various scenarios. The risk index values were the product of probability and severity, and on the basis of that, the risk of NOx emissions from vehicular sources was categorized into five indexes: extreme, acute, major, moderate and minor.

Table 2. Risk analysis matrix as a product of "severity of effects" and "probability of severity".

\begin{tabular}{ccccc}
\hline \multirow{2}{*}{ Probability } & \multicolumn{4}{c}{ Severity } \\
\cline { 2 - 5 } & Severe-4 & Critical-3 & Marginal-2 & Negligible-1 \\
\hline Strong-5 & Extreme (20) & Acute (15) & Major (10) & Minor (5) \\
High-4 & Acute (16) & Major (12) & Modest (8) & Minor (4) \\
Medium-3 & Major (12) & Modest (9) & Modest (6) & Minor (3) \\
Low-2 & Modest (8) & Modest (6) & Minor (4) & Minor (2) \\
Improbable-1 & Minor (4) & Minor (3) & Minor (2) & Minor (1) \\
\hline
\end{tabular}

\subsection{Probabilistic Spatial Distribution}

The results of emissions concentration and risk severity, calculated for different points in the city, were used to predict their city-wide spatial distribution. This was done using a spatial analysis tool (kriging option) in ARC GIS 10.5 that generates a probabilistic surface distribution from a scattered set of points. Since the scattered points in this research were well distributed to represent the city's behaviour, the spatial correlation considered in kriging was effective for portraying the variation between two points.

\section{Results and Discussions}

\subsection{Characteristics of Traffic Volumes}

As emissions are proportionately related to the number of vehicles, the mean traffic volumes along the roads provided a view of traffic characteristics on the roads. This is shown in Figure 8a, along with standard deviations for 46 road links in Dhaka City, which were obtained from 20,000 randomly generated samples. In general, the standard deviations were low in most of the road links, which meant that considering the average traffic volume per hour for each road link would be acceptable in mesoscale emissions modelling. This also indicated that the flow of traffic during peak and offpeak periods was consistent for most of the roads. However, a higher standard deviation was observed for the roads where the flow was inconsistent, meaning an extreme traffic flow (high or low) prevailed at some points of the day on those roads.

The results confirmed the dominance of private vehicles along the roads. In order to demonstrate the pattern more clearly, Figure $8 \mathrm{~b}$ provides on-road traffic volume data for some selected roads in the city. The dominance of CNG-fuelled buses over diesel-fuelled ones might have resulted due to the lower price of CNG and available technology. The growth trend of motorcycles, as shown in Figure 1, is also reflected in Figure 8, which could become even higher with time because of increased commercial advantages and incentives.

\subsection{Emissions and Their Probability}

As mentioned in the methodology section, the most updated vehicle-specific traffic volume data for all the major roads of the city are available for 2012, which were used to predict the road- and vehicle-specific traffic volume for 2018. Using the standard method of calculating emissions, and by varying the traffic volume and vehicle speed stochastically within the higher and lower range, the emissions for 2018 were calculated. The resulting NOx emissions were the product of 20,000 normally distributed random samples (20,000 scenarios), thus demonstrating a normal distribution of emissions and the probability density of each emission range (Figure 9a). As can be seen from the 
normal distribution curves of emissions, the higher kurtosis values for most of the roads indicate that a higher probability of occurrence would be around the mean value. Subsequently, the cumulative distribution capable of indicating the probability of emissions exceedance above the standard emissions limit (Figure 9b) demonstrates a higher probability of exceedance, as of 2018, for most of the roads. However, the results shown in Figure 8 are based on the average of both peak- and offpeak-period NOx emissions from vehicles, which might not demonstrate when and to what extent emissions exceedance takes place during a day. Therefore, to reduce risk severity on roads, later in this section, an emissions and risk index is demonstrated separately for both peak and offpeak periods that might be important in conceiving of a management plan for these two segments of the day.

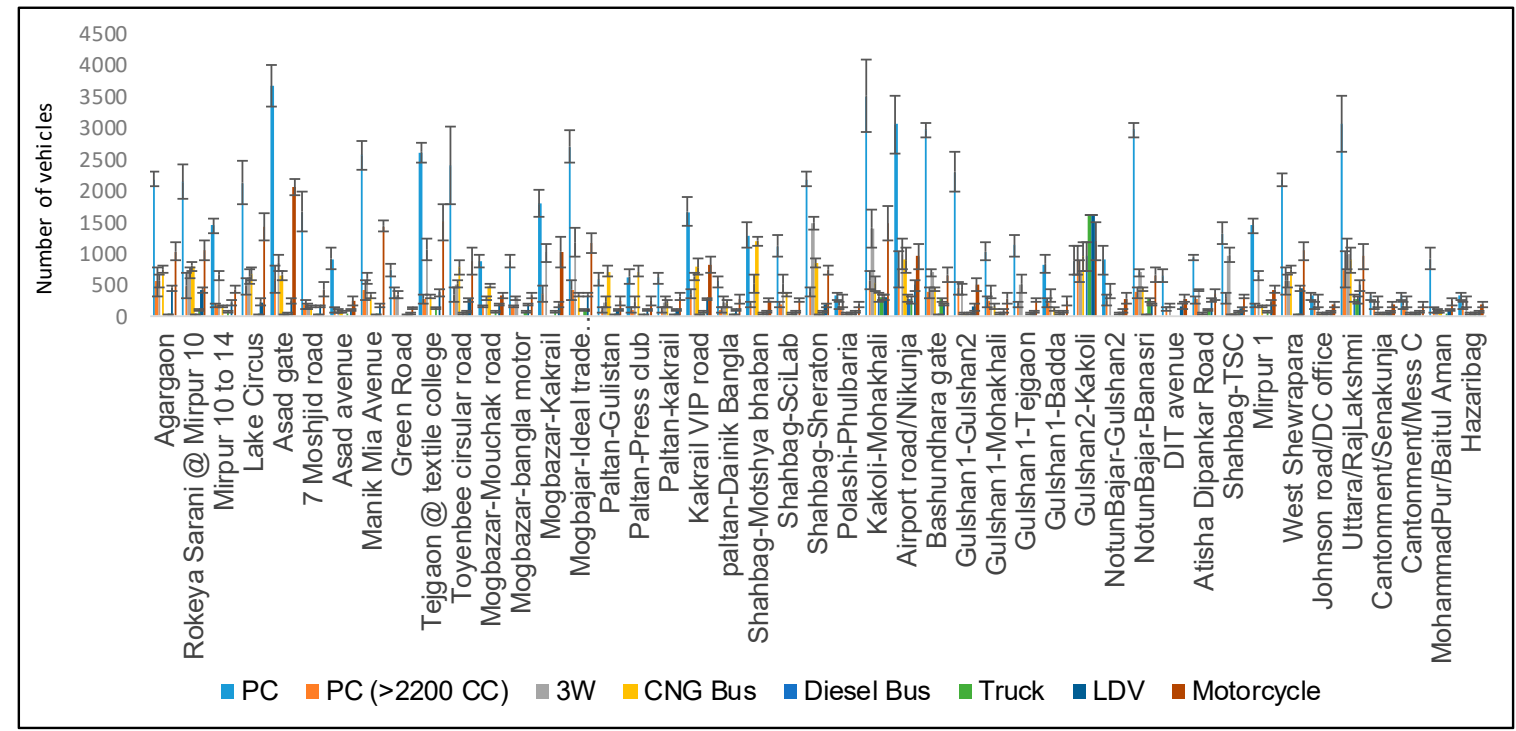

(a)

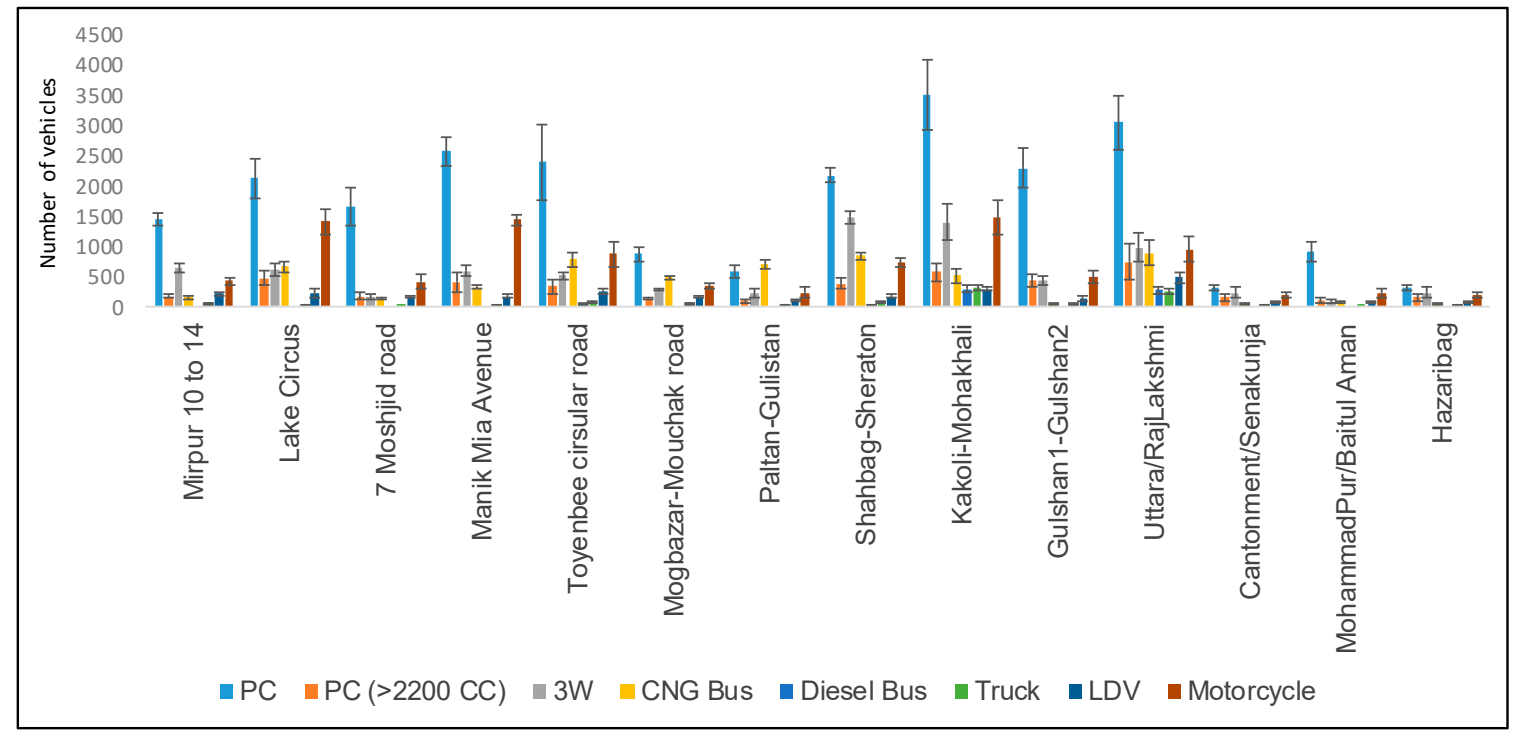

(b)

Figure 8. Mean and standard deviation of road- and vehicle-specific traffic volume data for 2012 (a) for all major roads of the city and (b) for selected arterial roads of the city. 


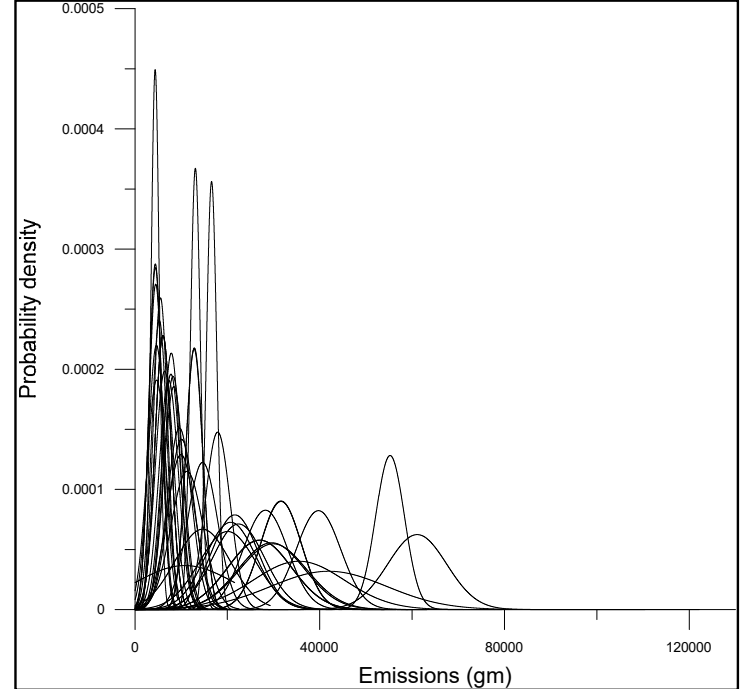

(a)

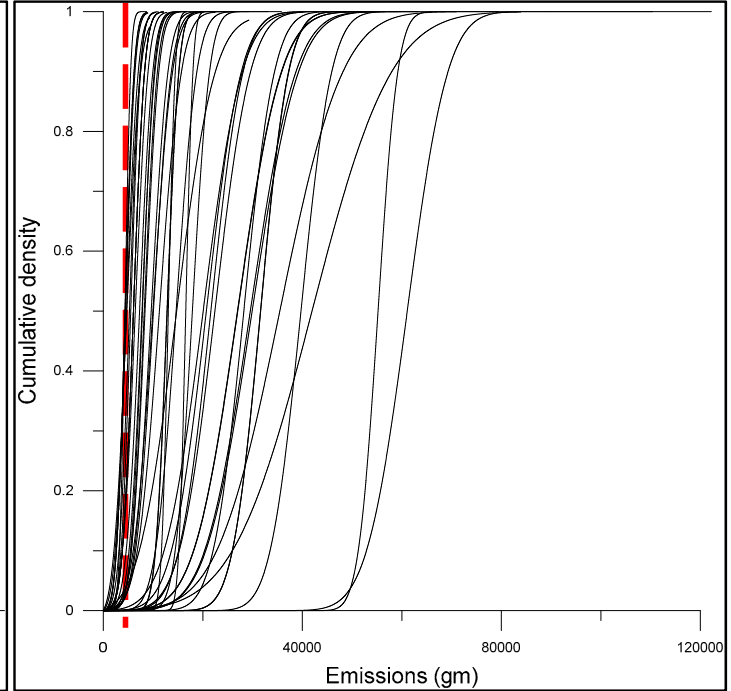

(b)

Figure 9. (a) Normal distribution of NOx emissions for different road links of Dhaka City, Bangladesh, for 2018; (b) cumulative distribution of normally distributed NOx emissions. Red dashed line indicates the emissions level corresponding to the national standard.

\subsection{Risk Severity on City Roads}

Urban dwellers travelling on roads are exposed to the emissions generated, and the extent of risk associated with being exposed to pollutants depends on the magnitude of emissions compared to the standard exposure limit. At the same time, the probability of being exposed to a certain level of emissions are also important while assessing risk. Therefore, as is outlined in the methodology section, the receptor (human) levels of NOx concentration at the sampling points were estimated. A spatial distribution of NOx concentrations over the city demonstrated the average hourly level (for both peak and off-peak periods) with a comparison to WHO guideline values for acute health effects ( $0.25 \mathrm{ppm})$ (Figure 10).
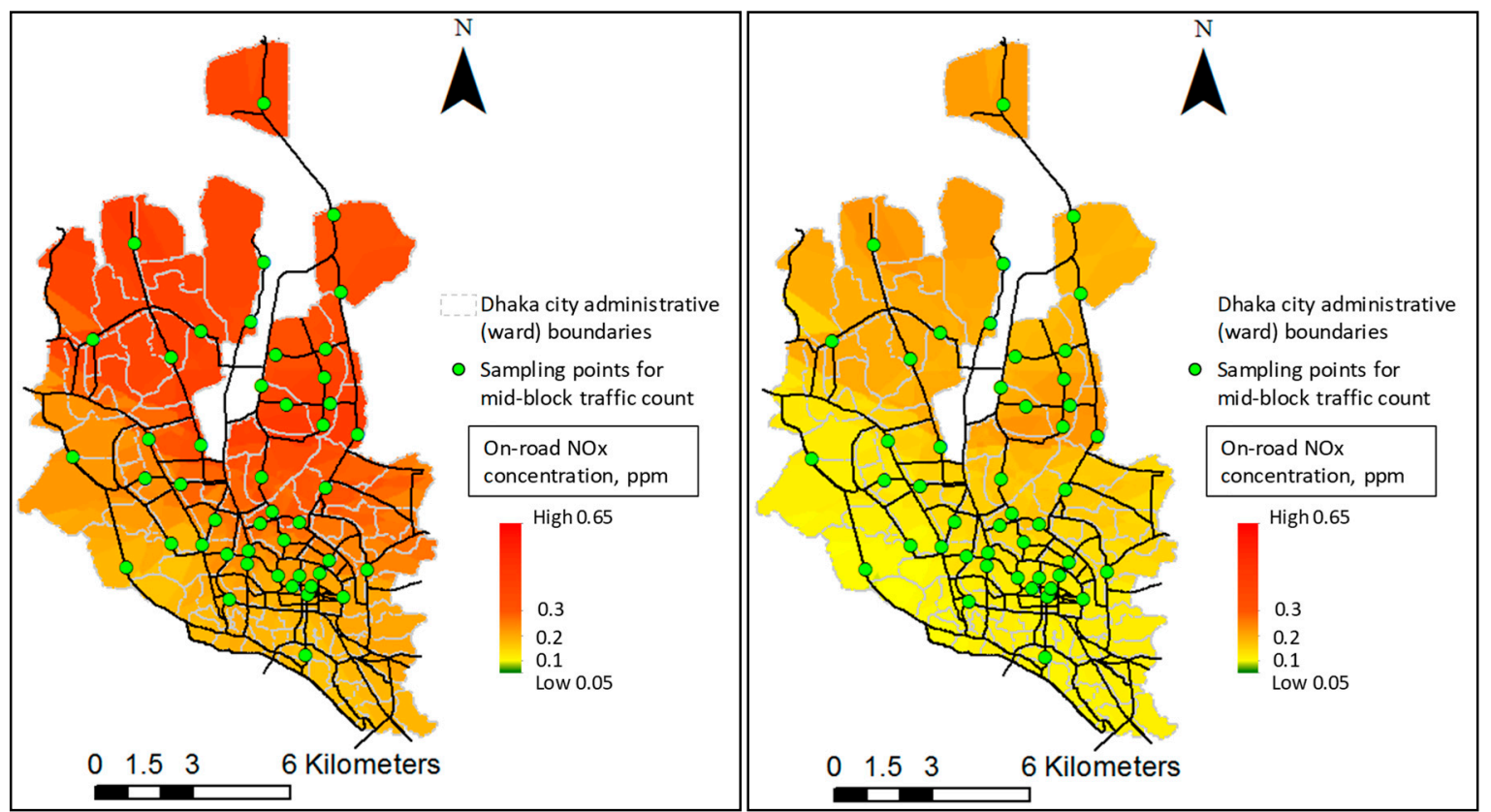

Figure 10. Probabilistic spatial distribution of on-road peak and offpeak NOx concentrations in 2018. 
The concentration shown in Figure 10 was obtained through a kriging interpolation of the modelling data, which estimated the probabilistic concentrations based on the modelling results of specified datapoints. Therefore, as expected, the probabilistic concentrations portrayed in Figure 10 were significantly lower than the modelling results. As is revealed in Figure 10, in 2018, dwellers of most of the roads (65\%) in Dhaka City were severely exposed to NOx concentrations during peak hours that made them vulnerable to acute health effects associated with that exposure. While around $10 \%$ of the roads had an exposure level that was marginal and perhaps not very harmful, the exposure to pollution on the rest of the roads was critical to dwellers during peak hours. The scenario during offpeak hours was relatively better, but still, for around $60 \%$ of the roads, the exposure level was above the critical level, while around $5 \%$ of the roads reached a severe level.

In order to assess the validity of the modelling results, they were compared to the available monitoring results of Dhaka City. The yearly average of the 24-h average concentration of NOx for 2018 was obtained from the monthly monitoring report for the Continuous Automatic Monitoring Station-2 site in Dhaka City. The modelling results from the same location were compared in order to have a logical comparison between the two. The 24-h average for the modelling site was obtained from averaging the peak and offpeak time concentrations. The comparison showed that modelling slightly overestimated the concentration ( $0.7 \mathrm{ppm}$ modelling vs. $0.6 \mathrm{ppm}$ monitoring), though in a range that could be considered acceptable when a number of factors are influential. The number of days of monitoring operations in a month might have affected the monitoring results. At the same time, the estimated input data for modelling might have been different from the site. However, considering the acceptable extent of difference, the model was not calibrated further based on the monitoring data and was considered valid for future scenario assessments.

Risk severity, considering the magnitude and probability of exposure, is therefore important to demonstrate to what extent the exposure scenarios might cause the risk. The extent of risk was assessed with a risk severity matrix (outlined in the methodology section), and a probabilistic spatial distribution of calculated risks during peak and offpeak hours in Dhaka City is provided in Figure 11.

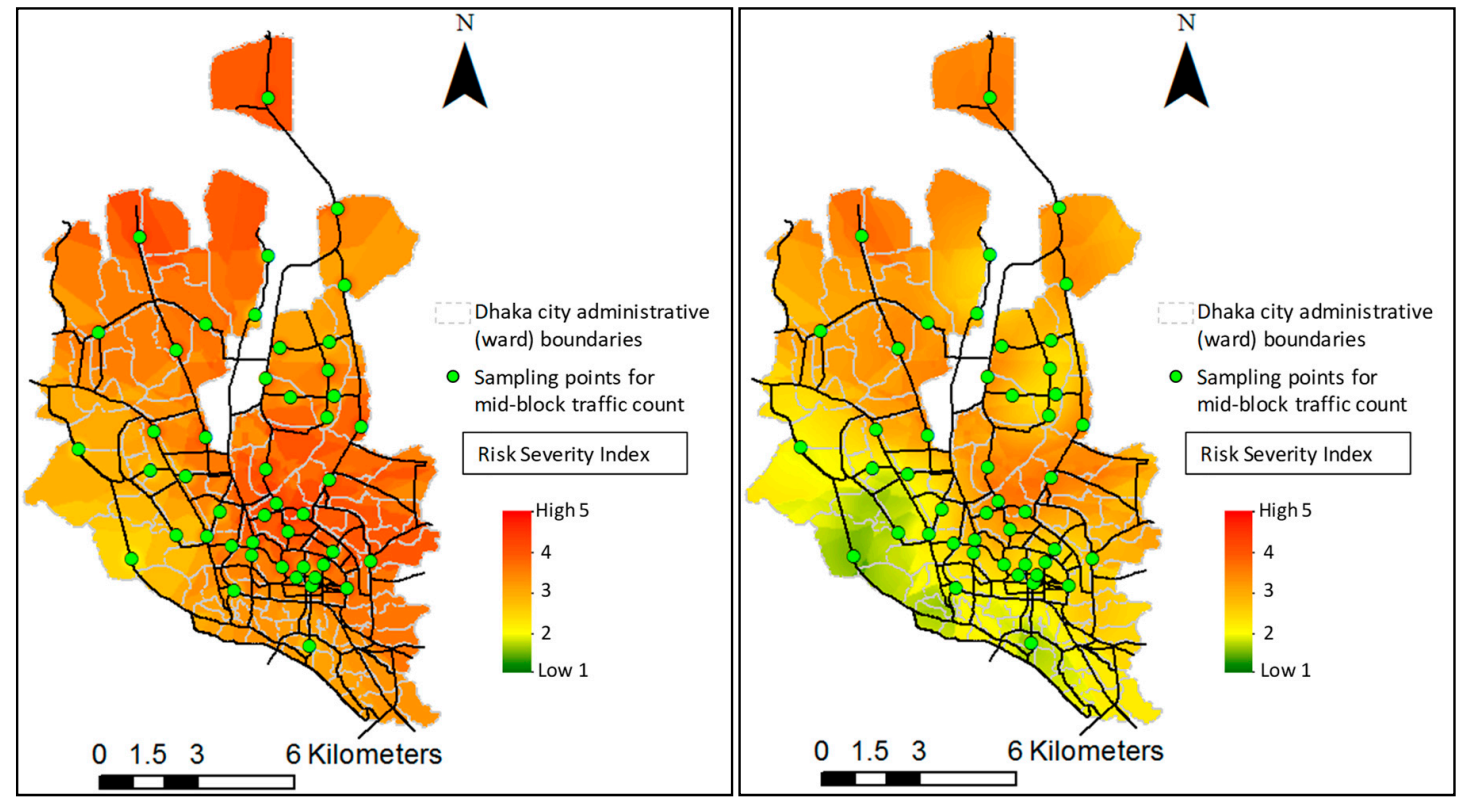

Figure 11. Probabilistic spatial distribution of on-road peak and offpeak risk severity in 2018 (Index: 5 = extreme, $4=$ acute, $3=$ major, $2=$ moderate and $1=$ minor $)$.

In line with the above critical magnitude of the exposure scenarios during peak time, the majority of the roads (around 80\%) were above the major risk level in Dhaka City, with around $45 \%$ being seriously risky (Figure 11). The risk factor decreased during the offpeak period, with around $50 \%$ 
being at or below major risk levels (Index 3) compared to 20\% during peak periods. However, some of the roads were found to have more or similar risk during offpeak periods, as those roads consistently accommodated a similar level of traffic volume throughout the day. In general, the roads around major commercial zones were at higher risk, indicating the consequence of mobility requirements that are satisfied with higher numbers of private vehicles. If travellers were to spend more than an hour every day on roads, considering the congestion level of the city, more than $60 \%$ of road dwellers would be at or over the level for major health risks, with more than $40 \%$ suffering seriously.

Inadequate public transport policies and planning strategies coupled with a latent demand for car travel might worsen the scenarios in five years. A business-as-usual risk scenario was predicted for 2024 (Figure 12) that considered a similar growth rate for private vehicles and public transportation and that assumed that the existing vehicle emissions standard would prevail and that traffic would operate in a similar pattern to now without consideration for any transport planning strategy to mitigate congestion. Although increasing the vehicle volume might affect the speed profile of vehicles, the speed profile was not adjusted for this scenario, as the current speed profile is already very low.

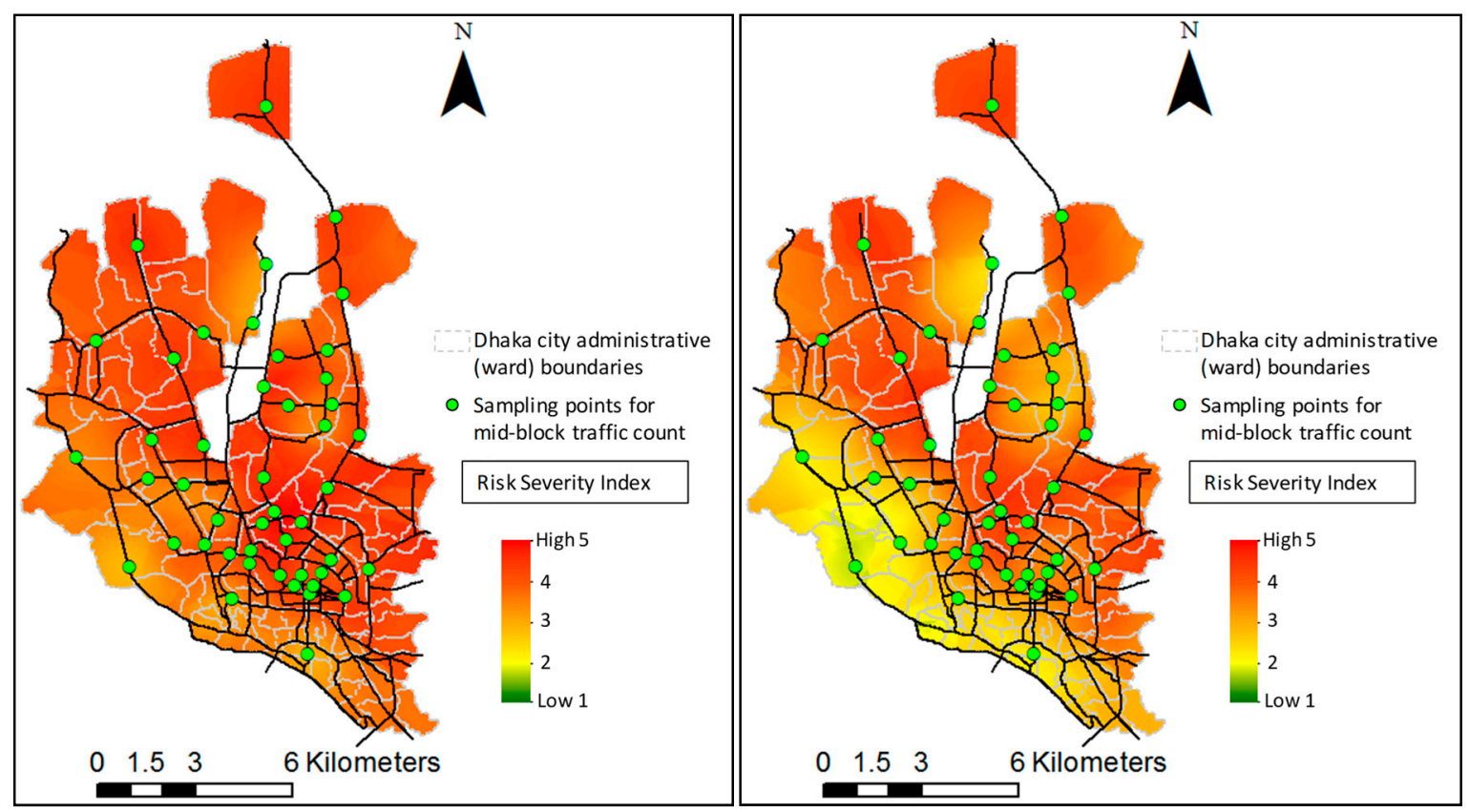

Figure 12. Probabilistic spatial distribution of predicted on-road peak and offpeak risk severity for the 2024 scenario: "business as usual" (Index: $5=$ extreme, $4=$ acute, $3=$ major, $2=$ moderate and $1=$ minor).

An incremental risk severity is expected for 2024 in a business-as-usual case, as the rate of emissions would increase with an increase in vehicle numbers. The prediction shows that there might be extremely risky zones around the commercial hubs, coupled with dwellers along more than two-thirds of the roads undergoing acute to extreme risks of health effects during peak time. For the offpeak period, there might be a lower risk severity; however, along most of the roads, dwellers would be at major risk for health effects (with acute risk along about one-third of roads), leaving very limited roads relatively safe for travelling. The roads that were predicted as safe are basically the roads in restricted zones or in highly congested market areas, where the mobility of motorized vehicles is limited. This scenario assessment is important in predicting future health risks if the current transport system prevails for the next five years without any planning or policy to improve the situation.

The government of Bangladesh has been revising the vehicle emissions standards for Dhaka City, which were set in 2005. The existing standards follow Euro 2 for gasoline/CNG vehicles and Euro 1 for diesel/heavy-duty vehicles, while the proposed standard for new registered vehicles would follow 
Euro 4 and Euro 3 standards, respectively [34]. Although the new emissions standards are proposed for implementation in 2019, they have not been strictly enforced yet. However, this research assumed a scenario for 2024 where new vehicles registered starting in 2019 would follow the new emissions standard (Figure 13). Considering the current trend of newly registered vehicles each year in each vehicle category [20], it was assumed that $50 \%$ of private vehicles, light-duty vehicles, buses and tracks; $70 \%$ of motorcycles; and $5 \%$ of three-wheeler vehicles running on the road would be under the new vehicle emissions standards. Although the assumption might not be an accurate one at this stage, we were still able to predict health risks for such a scenario (or scenarios close to this one).

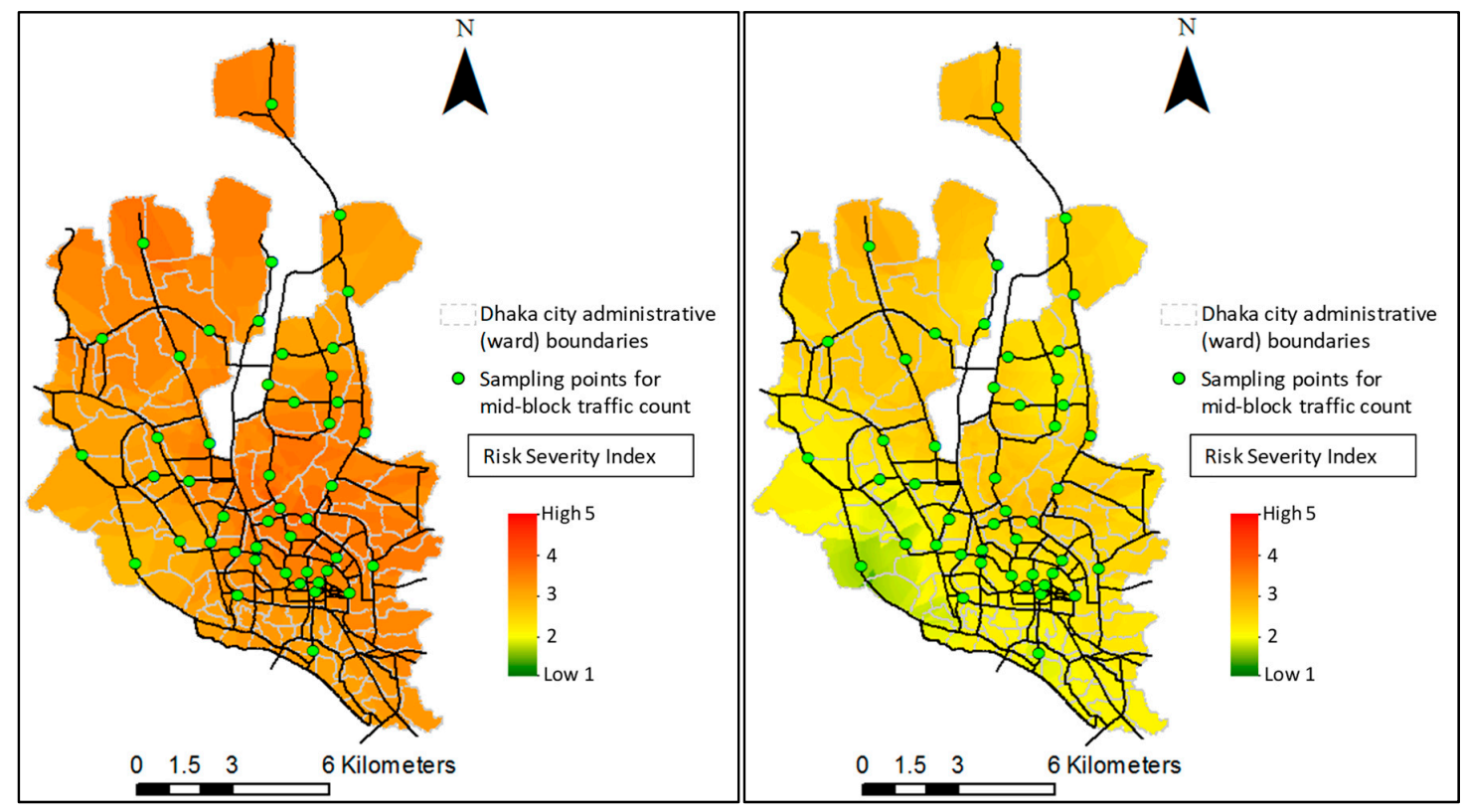

Figure 13. Probabilistic spatial distribution of predicted on-road peak and offpeak risk severity for the 2024 scenario: "incorporating proposed Euro emissions standards for new vehicles starting in 2019" (Index: 5 = extreme, 4 = acute, 3 = major, 2 = moderate and 1 = minor).

In such a scenario for 2024, with about half of vehicles being covered under new emissions standards, most of the areas would still remain at major risk levels during peak periods, while during offpeak periods, they would remain at moderate risk levels (Figure 13). The predictive assessment demonstrated that implementing the proposed emissions standards in the city might play a vital role in reducing risk, but it might not be enough for freedom from risk.

\subsection{Public Transport Planning and Urban Sustainability}

There has been construction going on for Mass Rapid Transit (MRT) and Bus Rapid Transit (BRT) routes in Dhaka City, which are expected to operate fully in 2024. This public transport project is likely to increase the mobility of people travelling with public transport to the major commercial hubs, transporting around 60,000 passengers per hour. At this stage, the trips would be covering only the major arterial routes of the city. Thus, if the feeder routes are not planned and integrated accordingly, the usage of private vehicles would still be encouraged.

This research assumed a scenario for 2024 that anticipated that $50 \%$ of private vehicle trips would be reduced for travel to work, as public transport in dedicated corridors might be a faster option compared to private vehicles. The scenario also expected that vehicle speeds would increase on roads due to a $50 \%$ reduction in private vehicles (the extent of the speed profile change is explained in the methodology section). This scenario was assumed to be consistent with previous research conducted by Iqbal et al. [35], which analysed the fact that efficient transport management practices along with a modal shift toward public transportation might be the consequence of such a scenario. The latent 
demand for car travel might affect the scenario more than was assumed, but justification for that is not within the scope of this study. This research predicts urban health standing (Figure 14) as an indicator of urban sustainability, in case such a transport scenario is achieved through integrated public transport planning and car-banning policies. In order to predict the effect of public transport planning and car-banning alone, this scenario also assumed that vehicles would operate by maintaining the existing Euro emissions standards.

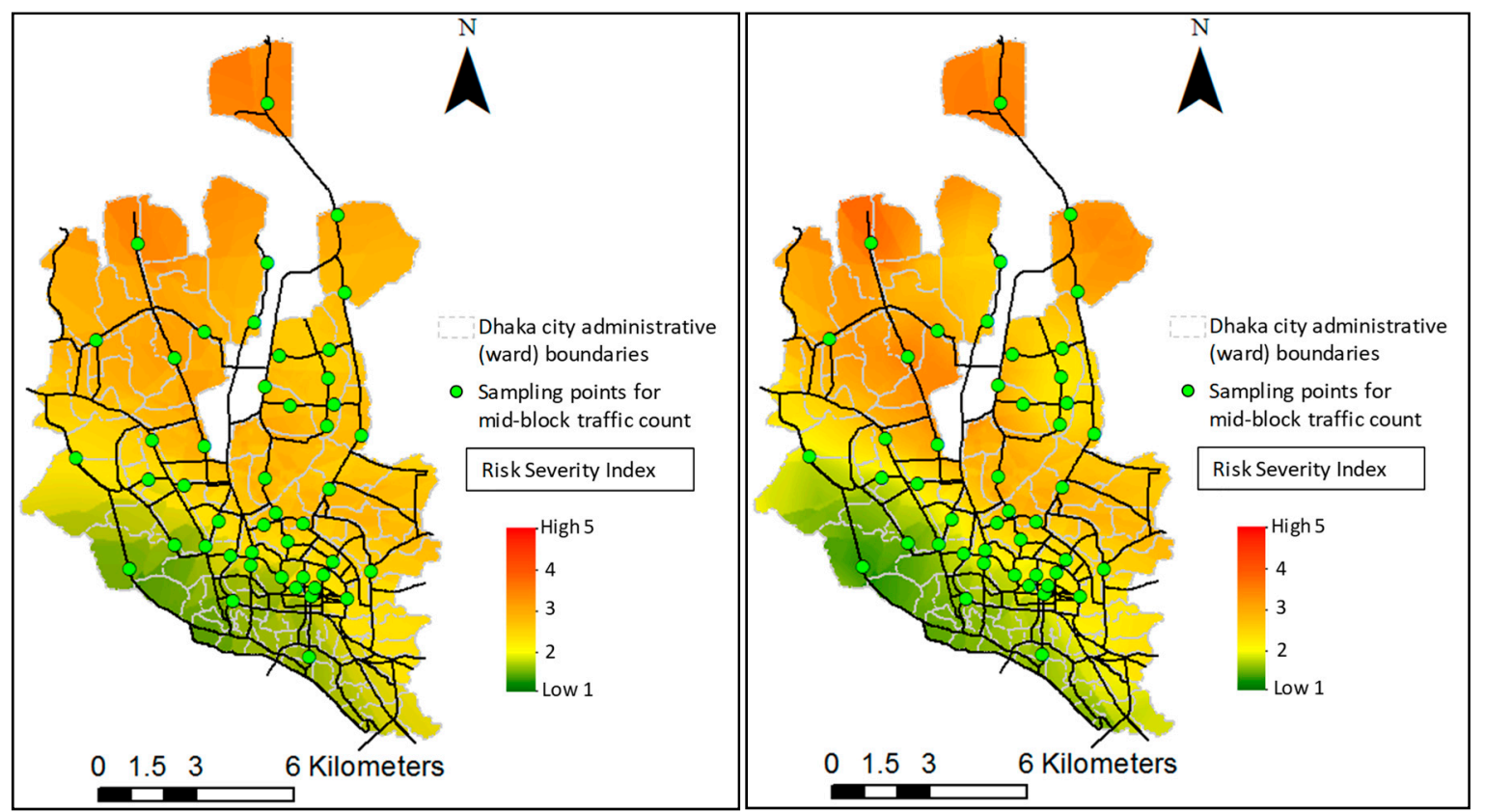

Figure 14. Probabilistic spatial distribution of predicted on-road peak and offpeak risk severity for the 2024 scenario: " $50 \%$ of private cars with the full implementation of Mass Rapid Transit (MRT)-Bus Rapid Transit (BRT) routes and vehicles maintaining existing emissions standards" (Index: $5=$ extreme, $4=$ acute, $3=$ major, 2 = moderate and $1=$ minor) .

The scenario predicted similar risks during peak and offpeak periods (Figure 14), even predicting higher risks along some of the roads during offpeak periods. This is interesting because the NOx concentrations predicted for peak periods were higher than for offpeak periods. However, the probability of occurrence of the predicted emissions concentrations was higher during the offpeak periods, which increased the risk during this period. As private vehicles were reduced by $50 \%$ in the scenario, the variability of private vehicles during offpeak periods was thus reduced, which resulted in a higher probability of the predicted emissions for this period in the majority of road links. Consequently, per the risk assessment matrix (Table 2), severe emission levels with high probabilities during peak time demonstrated levels of risk similar to off-peak times (strong probabilities with marginal severity).

Further segmentation of the risk assessment matrix could have differentiated the risk severity for the two periods. However, this was not restricted to demonstrate that such a dramatic change in the transport system (as assumed in the scenario) could only reverse urban health standing, yet major risk would persist along the majority of roads (around 60\%) during peak and offpeak hours. Although this scenario would not be risk-free, it would reduce the extent of risk, which is still a positive.

The scenario was further enhanced by incorporating the proposed Euro emissions standards for new vehicles starting in 2019, and the risk severity was assessed for that scenario (Figure 15). The results revealed that the risk severity would be minimized if a comprehensive integrated transport planning and vehicle emissions policy were to be implemented. For the assumed scenario, most of the areas of the city would fall under the minor risk zone during peak and offpeak periods in 2024, even though a portion of the city would still be at major risk. 


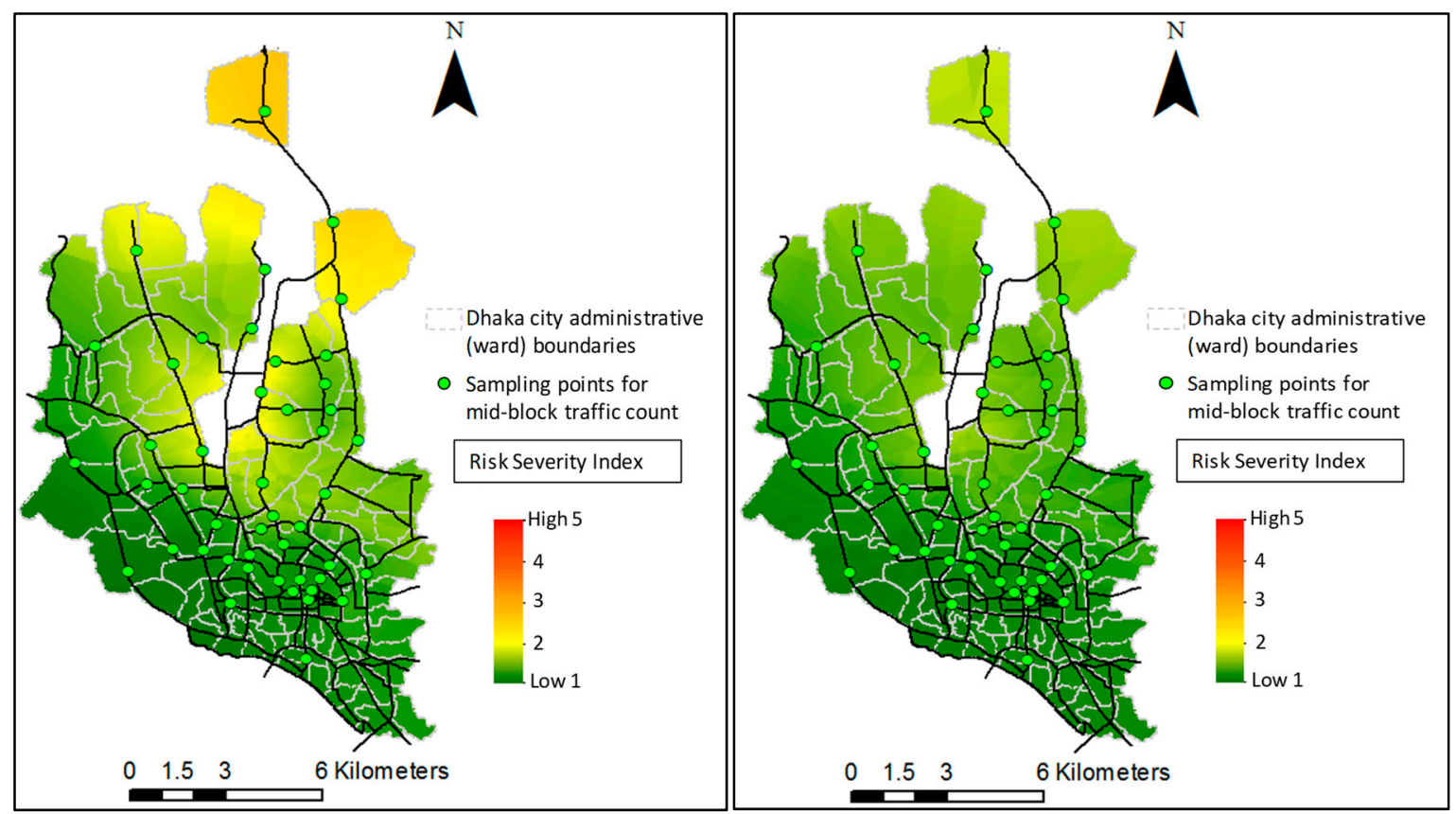

Figure 15. Probabilistic spatial distribution of predicted on-road peak and offpeak risk severity for the 2024 scenario: " $50 \%$ of private cars with the full implementation of full MRT-BRT routes and incorporating the proposed Euro emissions standards for new vehicles starting in 2019" (Index: $5=$ extreme, $4=$ acute, $3=$ major, $2=$ moderate and $1=$ minor $)$.

The scenarios assumed in this research might be overenthusiastic at this stage, but the analysis results demonstrate the fact that aggressive planning is required now in Dhaka. If the current trend in vehicle growth is supported, in five years (in 2024), any isolated strategy might not be enough to reduce the risk, as can be seen in Figures 13 and 14, and thus more aggressive planning would be required.

Given that the number of vehicles is one of the most important factors in increasing health risks, the latent demand for car travel needs to be controlled in Dhaka City. Appropriate transport planning and policy is required now, rather than trying to accommodate the growth of vehicles. Planning and policy options are beyond the scope of this research; however, decentralized facilities, urban sprawl supported by rapid transit options, connecting the existing masses with an efficient public transport system, an efficient traffic management system, strictly maintaining improved vehicle technology and controlling the movement of private vehicles might be some of the approaches that need to be thought of now. Unless hard and fast action is taken now, urban health standing and urban sustainability will be at risk in Dhaka and will be difficult to fix.

\section{Conclusions}

Health risks associated with transport air pollution are of major concern worldwide, especially when the appropriate transport planning is absent. There have been studies that have assessed the potential health effects of vehicular air pollution, while this research tried to focus on the probability of the effects and the extent of risks considering the WHO guideline values for human health. This probabilistic analysis was conducted so that a status of urban health could be measured, which was portrayed in this research. A stochastic modelling approach was adopted in this research to reduce the uncertainty of results caused by the limited number of available sampling data, and thus the modelling produced a result in close proximity to the available monitoring data. Only the risk associated with NOx emissions was considered in this study, thus leaving a scope for further research to assess risks for other emissions as well. While a critical urban health environment prevails at current transport scenarios in Dhaka City, the analysis pointed to the fact that the current trend of vehicular growth coupled with current vehicle technology and on-road traffic management systems might lead to an 
extremely risky urban health environment in five years, making it unsuitable for living. Better transport planning and appropriate policies are thus required to avoid this consequence. The scenarios analysed in this research (reduced private vehicle use supported by public transport modes and improved vehicle technology) could lead to appropriate transport planning options and could improve the risk scenario. The scenarios analysed here are hypothetical and were intended to demonstrate the risks if such scenarios prevail. However, the challenging part is achieving and maintaining such a reduced private vehicle usage scenario, since the vehicles would increase over time due to increased demand unless the numbers were strictly limited. Improving the functionality of the city might be important here so that demand does not overpower capacity. Therefore, more integrated research involving land use and transport planning, traffic management strategies and associated risk assessments might lead to a scenario that is promising for liveability and urban sustainability. A delay in planning might force the adoption of more aggressive strategies, which might not be socially acceptable and thus would fail to attain urban sustainability.

Author Contributions: Conceptualization, A.I. and M.M.R.; formal analysis, A.I. and S.A.; methodology, A.I. and M.M.R.; resources, A.I. and S.A.; validation, M.M.R.; writing—original draft, A.I.; writing-review and editing, S.A. and M.M.R.

Funding: This research received no external funding.

Conflicts of Interest: The authors declare no conflict of interest.

\section{References}

1. DTCB. BRT and Corridor Restructuring Implementation Study and Preliminary Design Work for the Uttara-Mohakhali-Ramna-SadarGhat Corridor in Dhaka: Interim Report; Dhaka Transport Coordination Board, Government of Bangladesh: Dhaka, Bangladesh, 2011.

2. Bluett, J.; Dey, K.; Fisher, G. Assessing Vehicle Air Pollution Emissions; Report Prepared for Department of the Environment, Water, Heritage and the Arts; Commonwealth of Australia, National Institute for Water and Atmospheric Research: Auckland, New Zealand, 2008.

3. BTRE. Health Impacts of Transport Emissions in Australia: Economic Costs; Working Paper 63; Bureau of Transport and Regional Economics, Australian Government: Canberra, Australia, 2005.

4. Chan, C.K.; Yao, X. Air pollution in mega cities in China. Atmos. Environ. 2008, 42, 1-42. [CrossRef]

5. EPA Victoria. Vehicle Emissions and Air Quality; Environment Protection Authority Victoria: Melbourne, Australia, 2019. Available online: https://www.epa.vic.gov.au/your-environment/air/vehicle-emissions-andair-quality (accessed on 14 August 2019).

6. Iqbal, A.; Allan, A.; Zito, R. Meso-scale on-road vehicle emission inventory approach: A study on Dhaka City of Bangladesh supporting the 'cause-effect' analysis of the transport system. Environ. Monit. Assess. 2016, 188, 149. [CrossRef] [PubMed]

7. Oanh, N.K.; Upadhyay, N.; Zhuang, Y.H.; Hao, Z.P.; Murthy, D.V.; Lestari, P.; Villarin, J.T.; Chengchua, K.; Co, H.X.; Dung, N.T.; et al. Particulate air pollution in six Asian cities: Spatial and temporal distributions, and associated sources. Atmos. Environ. 2006, 40, 2267-3380.

8. Shrestha, R.M.; Oanh, N.T.K.; Shrestha, R.P.; Rupakheti, M.; Rajbhandari, S.; Permadi, D.A.; Kanabkaeo, T.; Iyngararasan, M. Atmospheric Brown Cloud (ABC) Emission Inventory Manual; United Nations Environment Programme (UNEP): Nairobi, Kenya, 2013.

9. US EPA. Greenhouse Gas Emissions from a Typical Passenger Vehicle; United States Environment Protection Authority: Washington, DC, USA, 2019. Available online: https://www.epa.gov/greenvehicles/greenhousegas-emissions-typical-passenger-vehicle (accessed on 14 August 2019).

10. US EPA. 2014 National Emissions Inventory (NEI) Data; Version 2; United States Environment Protection Authority: Washington, DC, USA, 2019. Available online: https://www.epa.gov/air-emissions-inventories/ 2014-national-emissions-inventory-nei-data (accessed on 12 August 2019).

11. DEFRA. Trends in Primary Nitrogen Dioxide in the UK; Air Quality Experts Group, Department of Environment, Food, and Rural Affairs: London, UK, 2007.

12. Burgard, D.A.; Bishop, G.A.; Stedman, D.H.; Gessner, V.H.; Daeschlein, C. Remote Sensing of In-Use Heavy-Duty Diesel Trucks. Environ. Sci. Technol. 2006, 40, 6938-6942. [CrossRef] [PubMed] 
13. Xu, X.; Wang, L.; Niu, T. Air pollution and its health effects in Beijing. Ecosyst. Health 1998, 4, $199-209$. [CrossRef]

14. VTPI. Transportation Cost and Benefit Analysis-Air Pollution Costs; Victoria Transport Policy Institute: Victoria, BC, Canada, 2007.

15. Nakai, S.; Nitta, H.; Maeda, K. Respiratory health associated with exposure to automobile exhaust. II. Personal $\mathrm{NO}_{2}$ exposure levels according to distance from the roadside. J. Expo. Anal. Environ. Epidemiol. 1995, 5, 125-136. [PubMed]

16. Nitta, H.; Sato, T.; Nakai, S.; Maeda, K.; Aoki, S.; Ono, M. Respiratory Health Associated with Exposure to Automobile Exhaust. I. Results of Cross-sectional Studies in 1979, 1982, and 1983. Arch. Environ. Health Int. J. 1993, 48, 53-58. [CrossRef] [PubMed]

17. Frey, H.C.; Zheng, J.; Frey, H. Probabilistic Analysis of Driving Cycle-Based Highway Vehicle Emission Factors. Environ. Sci. Technol. 2002, 36, 5184-5191. [CrossRef] [PubMed]

18. Ryan, R.O.; Benavides, C.; Díaz, M.; Martín, J.P.S.; Mallea, J. Using probabilistic analysis to improve greenhouse gas baseline forecasts in developing country contexts: The case of Chile. Clim. Policy 2018, 19, 299-314. [CrossRef]

19. EEA. EMEP/EEA Air Pollutant Emission Inventory Guidebook; European Environment Agency: Copenhagen, Denmark, 2009. Available online: http://www.eea.europa.eu/publications/emep-eea-emission-inventoryguidebook-2009 (accessed on 4 August 2019).

20. BRTA. Registered Vehicles in Dhaka: Statistics; Bangladesh Road Transport Authority: Dhaka, Bangladesh, 2018. Available online: www.brta.gov.bd (accessed on 18 February 2019).

21. Maphill. Savanna Style Location Map of Bangladesh. 2019. Available online: http://www.maphill.com/ bangladesh/location-maps/savanna-style-map/ (accessed on 25 October 2019).

22. JICA. Preparatory Survey Report on Dhaka Urban Transport Network Development Study (DHUTS) in Bangladesh: Final Report (Appendix Volume); Japan International Cooperation Agency: Tokyo, Japan, 2010. Available online: http://open_jicareport.jica.go.jp/pdf/11996782_01.pdf (accessed on 2 September 2019).

23. Iqbal, A.; Allan, A. Modelling eco-efficiency for vehicular emissions from the perspective of dhaka city: Development of a tool for sustainable transport planning. In Proceedings of the 14th International Conference on Computers in Urban Planning and Urban Management, Cambridge, MA, USA, 7-10 July 2015.

24. CL4. User's Guide for CL4: A User Friendly Interface for the CALINE4 Model for Transportation Project Impact Assessments; California Line Source Dispersion Model Version 4 (CALINE4); California Department of Transportation: Sacramento, CA, USA, 1998.

25. US EPA. Preferred Dispersion Models; Support Center for Regulatory and Atmospheric Modeling, US Environment Protection Agency: Washington, DC, USA, 2011. Available online: https://www.epa.gov/scram/ air-quality-dispersion-modeling-preferred-and-recommended-models (accessed on 18 February 2019).

26. BMD. Statistics; Bangladesh Meteorological Department, Government of Bangladesh: Dhaka, Bangladesh, 2018.

27. World Weather Online. Dhaka Monthly Climate Averages. 2019. Available online: https://www. worldweatheronline.com/ (accessed on 29 August 2019).

28. Vallack, H. Male Declaration Project as a Part of Capacity Building Activity. In Emission Inventory for Bangladesh; United Nations Environment Programme (UNEP): Nairobi, Kenya; Regional Resources Center for Asia and Pacific (RRCAP): Pathumthani, Thailand, 2000.

29. Iqbal, A.; Oanh, N.T.K. Assessment of acid deposition over Dhaka division using CAMx-MM5 modeling system. Atmos. Pollut. Res. 2011, 2, 452-462. [CrossRef]

30. DoE. Clean Air and Sustainable Environment Project. In Monthly Air Quality Monitoring Report for 2018; Department of Environment, Ministry of Environment and Forests, Government of the People's Republic of Bangladesh: Dhaka, Bangladesh, 2018. Available online: http://case.doe.gov.bd/index.php?option=com content\&view $=$ article\&id=5\&Itemid $=9$ (accessed on 24 June 2019).

31. WHO. WHO Air Quality Guidelines for Particulate Matter, Ozone, Nitrogen Dioxide and Sulfur Dioxide; Global Update 2005; World Health Organization: Geneva, Switzerland, 2005.

32. ACS. Risk Rating and Assessment; American Chemical Society: Washington, DC, USA, 2019; Available online: https://www.acs.org/content/acs/en/chemical-safety/hazard-assessment/fundamentals/riskassessment.html (accessed on 24 June 2019). 
33. Garvey, P.R. Track 2: Implementing a Risk Management Process for a Large Scale Information System Upgrade-A Case Study. Insight 2001, 4, 15-22. [CrossRef]

34. DoE. Clean Air and Sustainable Environment Project. In Revisions of Vehicular Emission Standards for Bangladesh; Department of Environment, Ministry of Environment and Forests, Government of the People's Republic of Bangladesh: Dhaka, Bangladesh, 2012. Available online: http://case.doe.gov.bd/file_zone/ feedback/Revisions\%20of\%20Vehicular\%20Emission\%20Standards\%20for\%20Bangladesh.pdf (accessed on 15 May 2019).

35. Iqbal, A.; Allan, A.; Afroze, S. Analysis of transport eco-efficiency scenarios to support sustainability assessment: A study on Dhaka City, Bangladesh. Environ. Monit. Assess. 2017, 189, 366. [CrossRef] [PubMed]

(C) 2019 by the authors. Licensee MDPI, Basel, Switzerland. This article is an open access article distributed under the terms and conditions of the Creative Commons Attribution (CC BY) license (http://creativecommons.org/licenses/by/4.0/). 